\title{
Mitogen-Activated Protein Kinase-Activated Protein Kinase 2 (MK2) Contributes to Secondary Damage after Spinal Cord Injury
}

\author{
Nader Ghasemlou, ${ }^{1}$ Ruben Lopez-Vales, ${ }^{1}$ Claude Lachance, ${ }^{2}$ Thusanth Thuraisingam, ${ }^{2}$ Matthias Gaestel, ${ }^{3}$ \\ Danuta Radzioch, ${ }^{2}$ and Samuel David ${ }^{1}$ \\ ${ }^{1}$ Centre for Research in Neuroscience, and 2Department of Human Genetics, The Research Institute of the McGill University Health Centre, Montreal, \\ Quebec H3G 1A4, Canada, and ${ }^{3}$ Institute of Biochemistry, Hannover Medical School, 30625 Hannover, Germany
}

The inflammatory response contributes importantly to secondary tissue damage and functional deficits after spinal cord injury (SCI). In this work, we identified mitogen-activated protein kinase (MAPK)-activated protein kinase 2 (MAPKAPK2 or MK2), a downstream substrate of p38 MAPK, as a potential target using microarray analysis of contused spinal cord tissue taken at the peak of the inflammatory response. There was increased expression and phosphorylation of MK2 after SCI, with phospho-MK2 expressed in microglia/ macrophages, neurons and astrocytes. We examined the role of MK2 in spinal cord contusion injury using $M K 2^{-l-}$ mice. These results show that locomotor recovery was significantly improved in $M K 2^{-I-}$ mice, compared with wild-type controls. $M K 2^{-I-}$ mice showed reduced neuron and myelin loss, and increased sparing of serotonergic fibers in the ventral horn caudal to the injury site. We also found differential expression of matrix metalloproteinase- 2 and 9 in $M K 2^{-1-}$ and wild-type mice after SCI. Significant reduction was also seen in the expression of proinflammatory cytokines and protein nitrosylation in the injured spinal cord of $M K 2^{-I-}$ mice. Our previous work has shown that macrophages lacking MK2 have an anti-inflammatory phenotype. We now show that there is no difference in the number of macrophages in the injured spinal cord between the two mouse strains and little if any difference in their phagocytic capacity, suggesting that macrophages lacking MK2 have a beneficial phenotype. These findings suggest that a lack of MK2 can reduce tissue damage after SCI and improve locomotor recovery. MK2 may therefore be a useful target to treat acute SCI.

\section{Introduction}

The inflammatory response after injury is essential for clearance of tissue debris, tissue remodeling and repair. However, the inflammatory response after injury to the CNS, such as after spinal cord injury (SCI), can contribute to secondary tissue damage and thus increase functional loss (Blight, 1994; Kwon et al., 2005; Donnelly and Popovich, 2008; Popovich and Longbrake, 2008). This loss is permanent after SCI because of the limited capacity of the CNS for regeneration and self-renewal. The localized immune response after SCI, involving neutrophils, microglia/macrophages, and reactive astrocytes, contributes to this secondary damage (Giulian and Robertson, 1990; Taoka et al., 1997; Popovich et al., 1999, 2002; Tonai et al., 2001; Gris et al., 2004). Under such

Received June 11, 2010; revised July 29, 2010; accepted Aug. 11, 2010.

This work was supported by grants from the Canadian Institutes of Health Research (CIHR) to S.D. and D.R., and from the Deutsche Forschungsgemeinschaft to M.G. N.G. was the recipient of CIHR and Fonds de la Recherche en Santé du Québec Doctoral Studentships and R.L.-V. was a recipient of a CIHR Post-Doctoral Fellowship. We thank Ourania Tsatas and Hiba Kazak for technical support and Margaret Attiwell for help with illustrations.

Correspondence should be addressed to Dr. Samuel David, Center for Research in Neuroscience, Research Institute of the McGill University Health Center, Livingston Hall, Room L7-210, 1650 Cedar Avenue, Montreal, Quebec H3G 1A4, Canada. E-mail: sam.david@mcgill.ca.

R. L. Lopez-Vales' current address: Departament de Biologia Cellular, Fisiologia i Immunologia, Institut de Neurociències, Centro de Investigación Biomédica en Red sobre Enfermedades Neurodegenerativas (CIBERNED), Universitat Autònoma de Barcelona, 08193 Bellaterra, Catalonia, Spain.

DOI:10.1523/JNEUROSCI.2998-10.2010

Copyright $\odot 2010$ the authors $\quad 0270-6474 / 10 / 3013750-10 \$ 15.00 / 0$ conditions, these cells release various cytotoxic mediators, including proinflammatory chemokines/cytokines (McTigue et al., 1998; Rice et al., 2007), reactive oxygen species (Bao et al., 2004), and proteases (Noble et al., 2002; Wells et al., 2003b).

Injury and disease can elicit stress-related and inflammatory stimuli that activate the p38 mitogen-activated protein kinase (MAPK) pathway. p38 MAPK influences the production of proinflammatory cytokines, excitatory molecules, and mediators of oxidative stress (Saklatvala, 2004; Peifer et al., 2006). Previous studies have shown that p38 MAPK is expressed after SCI in microglia/macrophages, neurons and astrocytes, and is implicated in mediating chronic pain (Jin et al., 2003; Crown et al., 2008; Kobayashi et al., 2008). However, p38 MAPK also mediates a variety of cellular functions involved in development, cell survival and proliferation (Roux and Blenis, 2004; Krens et al., 2006). Studies inhibiting p38 MAPK after SCI have shown differing results, from slightly improved outcome (i.e., increased standing frequency) and reduced apoptosis (Horiuchi et al., 2003; Z. Xu et al., 2006) to no improvements in locomotor recovery (Stirling et al., 2008). The inhibitors used against p38 MAPK can block both its beneficial and detrimental effects, which may account for these ambiguous results and may also reflect feedback control of p38 in its kinase cascade (for review, see Gaestel et al., 2009). MK2, which is downstream of p38 MAPK, may therefore be a better candidate for therapeutic intervention, as its in- 
hibition would likely have fewer detrimental effects than would the inhibition of p38 MAPK.

MK2 is activated by phosphorylation (Gaestel, 2006), resulting in the increased production and activation of matrix metalloproteinases (MMPs) (L. Xu et al., 2006), proinflammatory cytokines (Kotlyarov et al., 1999; Winzen et al., 1999), and nitric oxide (Thuraisingam et al., 2007). MK2 knock-out mice show reduced neurotoxicity and neuroinflammation in models of Parkinson's disease (Thomas et al., 2008) and cerebral ischemia (Wang et al., 2002), and in in vitro models of Alzheimer's disease (Culbert et al., 2006). The phosphorylated form of MK2 (pMK2) has been localized to microglia and astrocytes under these conditions. In this study, we identified MK2 as a gene of interest at the peak of the inflammatory response after SCI using pathway analysis of microarray data from contused mouse spinal cords. We assessed the cell type-specific expression of pMK2 after SCI, and evaluated its contribution to tissue damage and locomotor recovery using $M K 2^{-1-}$ mice.

\section{Materials and Methods}

Spinal cord injury. Age-matched adult female $M K 2^{-1-}$ (Kotlyarov et al., 1999) and control wild-type mice were used. Female C57BL/6 mice ( 8 weeks of age) were used for the Affymetrix GeneChip analysis (see below). The protocol for spinal cord contusion injuries was similar to that previously reported (Ghasemlou et al., 2005). Briefly, mice were anesthetized using ketamine/xylazine/acepromazine $(50: 5: 1 \mathrm{mg} / \mathrm{kg}$ ) and a partial laminectomy done at vertebral level T11. The adjacent vertebrae were immobilized using serrated Adson forceps (Fine Science Tools) and the spinal cord contused using the Infinite Horizons spinal cord impactor (Precision Scientific). All contusions were moderate injuries with impact force of $50 \pm 5 \mathrm{kdyn}$ and tissue displacement of 400-600 $\mu \mathrm{m}$. Animals were killed at 1, 3, 7, 14 and $28 \mathrm{~d}$ postinjury for RNA and protein analysis ( $n=3-4$ per group per time point); at $12 \mathrm{~h}$ and $7 \mathrm{~d}$ postinjury for histological analysis ( $n=3-6$ per group per time point); and at $28 \mathrm{~d}$ after injury for locomotor and histological analyses $(n=10-11$ per group). All protocols were approved by the McGill University Animal Care Committee and followed the guidelines of the Canadian Council on Animal Care.

GeneChip hybridization. Two groups of C57BL/6 mice were used for Affymetrix GeneChip expression studies: laminectomized controls and spinal cord contusion injury. Animals were killed $7 \mathrm{~d}$ after surgery and a $5 \mathrm{~mm}$ length of the spinal cord centered on the lesion site removed and snap-frozen in liquid nitrogen. Spinal cords from experimental and control groups were pooled separately for each GeneChip and 3 GeneChips were done for each group (spinal cords of 6 mice were pooled per chip). The frozen tissue was homogenized in QIAzol reagent (Qiagen) using the RNeasy Lipid Tissue kit, as per manufacturer's directions. RNA purities were analyzed before hybridization using a BioAnalyzer 2100 (Agilent) and only samples without DNA, degraded RNA or salt contamination were used. The RNAs were amplified and hybridized onto Mouse 4302.0 GeneChips (Affymetrix) as per manufacturer's instructions. This work was performed at the McGill University Genome Centre.

GeneChip analysis. Resultant Affymetrix CEL data files, which store the results of the intensity calculations on the pixel values from GeneChips, were normalized using RMAExpress v.0.4.1, log-transformed, and expression values saved for further analysis. Statistical analysis was performed using MeV 4.0 (TM4) with $t$ tests performed at $p<0.05$ and genes showing significant changes in expression saved for annotation. For comparisons between groups, only those genes whose expression had changed by 1.5 -fold or greater were used. Annotation was performed by extracting data from the corresponding Affymetrix GeneChip annotation file with a custom program (ProbesetExtractor, Diploide BioIT) written in Java. Gene ontology (GO) terms were classified using the Gene Ontology Tree Manager (GOTM) (Zhang et al., 2004) and the Kyoto Encyclopedia of Genes and Genomes (KEGG) (Kanehisa and Goto, 2000). Pathways were analyzed using WebGestalt from GOTM and Fatigo + from Babelomics (Al-Shahrour et al., 2005).
Locomotor analysis. Locomotor outcome after spinal cord contusion injury was assessed using the Basso Mouse Scale (BMS) (Basso et al., 2006 ). Mice ( $n=10-11$ per group) were scored in an open-field environment by two individuals blind to experimental conditions and trained in BMS analysis in Dr. Michelle Basso's laboratory at Ohio State University. Consensus scores for each animal were averaged at each time point for a maximum of 9 points for the BMS score and 11 points for the subscore, which assesses finer aspects of locomotion. This analysis was done in two separate cohorts of mice. Only animals used for locomotor analysis were used for histological analysis at day 28.

Histological analysis. Mice ( $n=10-11$ per group) were deeply anesthetized and killed by transcardial perfusion with $4 \%$ paraformaldehyde in $0.1 \mathrm{M}$ phosphate buffer $(\mathrm{PB})$. A $5 \mathrm{~mm}$ length of spinal cord was removed, centered on the epicenter of injury, postfixed for $1 \mathrm{~h}$, cryoprotected in $30 \%$ sucrose in $0.1 \mathrm{M} \mathrm{PB}$ for $48 \mathrm{~h}$ and serial $14 \mu \mathrm{m}$ cryostat sections picked-up on glass slides. The following primary antibodies were used for immunofluorescence labeling: rabbit anti-phospho-MK2 (1: 200; Cell Signaling Technology); rat monoclonal anti-CD11b (Mac-1) (for microglia/macrophages; 1:200; Serotec); rat monoclonal antineutrophils 7/4 (1:200; Abcam); rat polyclonal anti-GFAP (for astrocytes; 1:10,000; Dako); mouse monoclonal anti-NeuN (for neurons; 1:1000; Invitrogen); and rabbit anti-5HT (1:5000; Sigma-Aldrich). Tissue sections were incubated with the following secondary antibodies: donkey anti-rat IgG conjugated to Alexa Fluor594 (1:400; Invitrogen); goat anti-mouse IgG conjugated to rhodamine (tetramethylrhodamine isothiocyanate) (1:200; Jackson ImmunoResearch); and/or goat antirabbit IgG conjugated to AlexaFluor488 (1:400; Invitrogen). Tissue sections were first blocked with an anti-mouse IgG antibody (1:100; Jackson ImmunoResearch) for $2 \mathrm{~h}$ when immunostaining with an antibody generated in mouse. A rabbit polyclonal antibody against 3-nitrotyrosine (1:400; Millipore) was used to identify nitric oxide-mediated damage and its binding was revealed using HRP-conjugated secondary antibody and the chromogen diaminobenzidine, as previously described (Rathore et al., 2008). Tissue sections were stained with Luxol Fast Blue (LFB) to assess myelin loss and with cresyl violet to assess neuron loss in the ventral horn. Analysis of cell type-specific immunostaining $(n=6)$ and markers of tissue injury $(n=9-11)$ were then carried out.

Western blot analysis. A $5 \mathrm{~mm}$ length of the spinal cord centered on the epicenter of injury was removed and snap-frozen in liquid nitrogen $(n=$ 3 per group). The tissues were then homogenized in radioimmunoprecipitation (RIPA) buffer with protease and phosphatase inhibitors (Jeong and David, 2003). Protein concentration was determined and the samples (40 $\mu \mathrm{g}$ each) were separated on $4-12 \%$ gradient or $10 \%$ SDSpolyacrylamide gels (Invitrogen) and transferred onto polyvinylidene difluoride membranes (Millipore). The membranes were blocked for $4 \mathrm{~h}$ in $5 \%$ powdered milk in PBS containing 0.05\% Tween 20 (PBS-T), and incubated with one of the following primary antibodies overnight at $4^{\circ} \mathrm{C}$ : rabbit anti-phospho-MK2 (1:200), rabbit anti-MK2 (1:200), rabbit antiphospho-p38 (1:200), rabbit anti-p38 (1:200), rabbit anti-human phospho-Hsp27 (which recognizes mouse pHsp25; 1:200), or rabbit anti-human Hsp27 (which also recognizes mouse Hsp25; 1:200). All primary antibodies used were purchased from Cell Signaling Technology. Membranes were washed in PBS-T and incubated with goat anti-rabbit horseradish peroxidase (HRP)-conjugated secondary antibody (1:300,000; Jackson ImmunoResearch). The membranes were washed again in PBS-T and the binding of HRP-conjugated antibodies detected by chemiluminescence (Western Lightning Chemiluminescence Reagent Plus, PerkinElmer). Membranes were reprobed with monoclonal mouse anti- $\beta$-actin (1:300, Sigma-Aldrich) to ensure equal loading of samples. The films were scanned and the changes in protein expression levels between wild-type and MK2 $2^{-1-}$ samples quantified as a ratio of the $\beta$-actin levels using ImageQuant 5.0 software.

Multiplex analysis of cytokine protein expression. A $5 \mathrm{~mm}$ length of spinal cord from contused wild-type and $M K 2^{-1-}$ mice ( $n=3$ per group) were removed $12 \mathrm{~h}$ after injury and snap-frozen. The tissue was homogenized in PBS with protease and phosphatase inhibitors, and protein concentrations measured using the Lowry method (Bio-Rad). Equal protein samples from all groups were concentrated using MicroCon centrifugation tubes (Millipore) and resuspended to a total of $80 \mu \mathrm{l}$ per sample. The protein 
concentrations of 20 chemokines/cytokines were then analyzed using the BioSource Mouse Cytokine 20-Plex Multiplex Bead Immunoassay (Invitrogen) on a Luminex-100LS system, as per the manufacturer's protocol. Results were analyzed using Beadview multiplex data analysis software (Millipore). Protein levels are presented as mean \pm SD.

Gelatin zymography. Spinal cord segments $5 \mathrm{~mm}$ in length centered around the lesion epicenter from contused wild-type and $M K 2^{-1-}$ mice ( $n=3$ per genotype) were removed and snap-frozen at $7 \mathrm{~d}$ postinjury and gelatin zymography performed, as previously described (Hsu et al., 2006). Tissues were homogenized in RIPA buffer, as above, and $10 \mu \mathrm{g}$ of protein from each sample was loaded onto a $10 \%$ Novex gelatin zymogram gel (Invitrogen) and separated by electrophoresis at $4^{\circ} \mathrm{C}$ at $125 \mathrm{~V}$. The gels were placed in Renaturing Buffer for $1 \mathrm{~h}$, followed by Developing Buffer for $48 \mathrm{~h}$ at $37^{\circ} \mathrm{C}$ and then stained with $0.05 \%$ Coomassie Blue for $30 \mathrm{~min}$. The gel was then destained using a 30\% methanol/10\% acetic acid mixture. Clear bands indicative of matrix metalloproteinases were identified by their molecular weight.

Macrophage phagocytosis assay. Bovine myelin (1 mg/ml) was incubated with the lipophilic fluorescent dye $1,1^{\prime}$-dioctadecyl-3,3,3', $3^{\prime}$ tetramethylindocarbocyanine perchlorate (DiI) (Invitrogen) at a final concentration of $12.5 \mu \mathrm{g}$ of DiI $/ \mathrm{mg}$ of myelin for $30 \mathrm{~min}$ at $37^{\circ} \mathrm{C}$. Excess DiI was removed by washing the labeled myelin with PBS. MK2 ${ }^{+/+}$and $M K 2^{-1-}$ macrophage cell lines (Thuraisingam et al., 2007) were then plated into 24 -well plates $\left(5 \times 10^{5}\right.$ cells per well $)$ and incubated overnight at $37^{\circ} \mathrm{C}$. Twenty micrograms of DiI-labeled myelin was added to the wells for $1 \mathrm{~h}$ at $37^{\circ} \mathrm{C}$. Noningested or unbound myelin was removed by washing the plates 3 times with sterile PBS. Macrophages were then triturated off the wells and collected. Mean fluorescent intensity and the percentage of fluorescent cells were determined by fluorescence activated cell sorting (FACS) analysis using a FACSCalibur (BD Biosciences). Experiments were repeated three times.

Quantification. Analyses of histological sections were performed using the BioQuant Image Analysis System on a Zeiss AxioSkop2 microscope. The epicenter of injury in all spinal cords was identified using Mac- 1 and GFAP immunoreactivity. Myelin loss in the dorsal column was measured using LFB-stained cross-sections of the spinal cord. The threshold feature of BioQuant was used to measure the area of spared myelin within a preset area placed directly over and within the dorsal column. The ratio of spared myelin to the preset area was measured at $\sim 200 \mu \mathrm{m}$ intervals over a $2 \mathrm{~mm}$ length of the cord. Ventral horn neurons were also measured at these regular intervals. For neuronal counts, values represent the sum of cresyl violet-stained neurons in the left and right ventral horns. Serotonergic (5-HT) immunoreactivity was also measured using the threshold feature of the BioQuant Image Analysis System to identify the pixel density representing all immunopositive axons in the ventral horn $1 \mathrm{~mm}$ caudal from the injury site. Neutrophil numbers at $1 \mathrm{~d}$ postinjury in cross-sections of the spinal cord were counted using 7/4 immunoreactivity and DAPI to label the nucleus. Neutrophils were counted in three spinal cord sections $\sim 100 \mu \mathrm{m}$ apart, centered at the epicenter of injury. Protein levels and MMP activity were analyzed by quantifying digitized images of gels using ImageQuant 5.0 software. Comparisons of two datasets were analyzed by Student's $t$ test, while data with $>2$ variables (i.e., over time or distance) were analyzed by two-way repeated-measures (RM) ANOVA with post hoc Tukey tests. All data are plotted as mean \pm SE unless otherwise specified. Locomotor analysis was performed in two cohorts of mice, which were used for subsequent histological analysis.

\section{Results}

Pathway-specific analysis of spinal cord injury microarray data

Affymetrix GeneChip analysis was performed to identify pathways up- and downregulated in the spinal cord $7 \mathrm{~d}$ after contusion injury. Previous studies have identified day 7 after SCI as the peak of the macrophage response (Sroga et al., 2003). Gene expression changes in the spinal cord between laminectomized controls and contused C57BL/6 mice were analyzed using Robust Multiarray Average (RMA) analysis (Irizarry et al., 2003). Of the 45,101 transcripts present on the Affymetrix Mouse $4302.0 \mathrm{Ge}$ -
Table 1. Number of genes in KEGG pathways showing the greatest number of genes significantly upregulated ( $p<0.05 ; 1.5$-fold or greater) $7 \mathrm{~d}$ after spinal cord injury, relative to laminectomized controls

\begin{tabular}{ll}
\hline KEGG pathway & Number of genes \\
\hline Cytokine- cytokine receptor interaction & 46 \\
Focal adhesion & 42 \\
MAPK signaling pathway & 36 \\
Regulation of actin cytoskeleton & 29 \\
ECM-receptor interaction & 28 \\
Leukocyte transendothelial migration & 27 \\
Cell adhesion molecules (CAMs) & 25 \\
Hematopoietic cell lineage & 23 \\
Toll-like receptor signaling pathway & 23 \\
Jak-STAT signaling pathway & 22 \\
B cell receptor signaling pathway & 22 \\
\hline
\end{tabular}

Table 2. Top 20 genes from the KEGG MAPK signaling pathway significantly upregulated $7 \mathrm{~d}$ after spinal cord injury, listed by $p$ value

\begin{tabular}{lll}
\hline Gene name & $p$ value & Fold change \\
\hline Caspase 1 & 0.00032 & 2.45 \\
MAPK-activated protein kinase 2 & 0.00244 & 1.68 \\
Mitogen-activated protein kinase kinase kinase 3 & 0.00416 & 1.56 \\
Caspase 3 & 0.00449 & 1.84 \\
Related RAS viral (r-ras) oncogene homolog 2 & 0.00497 & 1.73 \\
Filamin C, $\gamma$ (actin binding protein 280) & 0.00536 & 1.98 \\
Mitogen-activated protein kinase kinase kinase 1 & 0.00594 & 1.70 \\
Epidermal growth factor receptor & 0.00596 & 1.78 \\
Growth arrest and DNA damage-inducible 45 $\alpha$ & 0.00810 & 2.17 \\
Caspase 7 & 0.00924 & 2.08 \\
Caspase 6 & 0.01110 & 1.59 \\
Platelet-derived growth factor receptor, $\beta$ polypeptide & 0.01133 & 2.29 \\
Caspase 8 & 0.01217 & 2.25 \\
Activating transcription factor 4 & 0.01219 & 1.64 \\
Interleukin 1 $\alpha$ & 0.01234 & 1.76 \\
Caspase 4 & 0.01495 & 2.47 \\
Mitogen-activated protein kinase kinase kinase 8 & 0.01574 & 1.78 \\
Nuclear factor of $\kappa$ light polypeptide gene enhancer in B-cells 2 & 0.01620 & 1.60 \\
Transforming growth factor, $\beta$ 1 & 0.01764 & 2.23 \\
Jun oncogene & 0.01913 & 1.65 \\
\hline
\end{tabular}

neChip, 2300 were upregulated and 2098 downregulated by $>1.5$-fold $(p<0.05)$ in the contused spinal cord relative to the laminectomized controls. Due to the large numbers of transcripts whose expression were significantly altered, we used the Kyoto Encyclopedia of Genes and Genomes (KEGG) Pathway analysis to identify genes of interest (Kanehisa and Goto, 2000).

The top 10 pathways with the largest numbers of genes upregulated are listed in Table 1. Among the pathways identified are those related to the inflammatory response, and cell adhesion/ migration. One of the pathways with the greatest changes in gene expression is the mitogen-activated protein kinase (MAPK) signaling pathway. The localization of several of these molecules within the cell is shown in the KEGG pathway diagram in supplemental Figure 1 (available at www.jneurosci.org as supplemental material). The top 20 upregulated genes of this pathway, sorted by $p$-value, are listed in Table 2 and include genes which have previously been shown to have significant effects in SCI. These include caspase 1 (de Rivero Vaccari et al., 2008), transforming growth factor- $\beta 1$ (Hamada et al., 1996), epidermal growth factor receptor (Erschbamer et al., 2007), and IL-1 $\alpha$ (Tonai et al., 1999). One of the genes furthest downstream in this pathway, and therefore likely to have more selective biological effects, is MK2, which also has the second lowest $p$-value in the list (Table 2). Due to the role of p38 
A

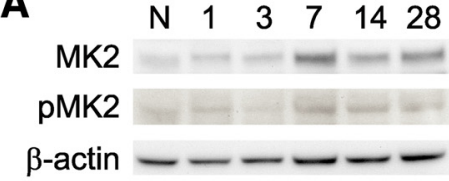

pMK2/NeuN
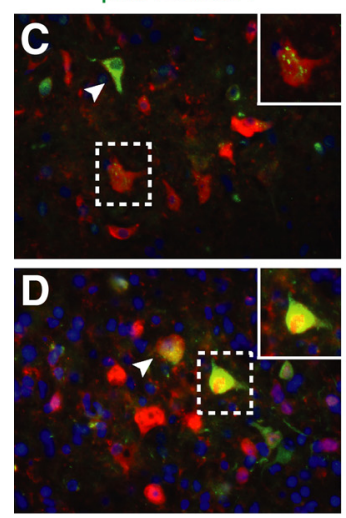

E
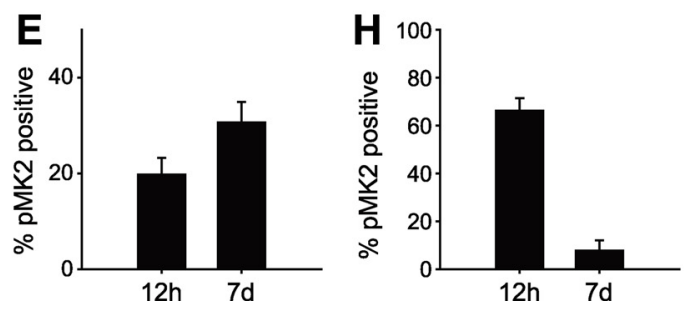

Figure 1. $\quad A$, Western blots for total and pMK2 in naive (N) spinal cord and at 1,3,7, 14 and $28 \mathrm{~d}$ after SCl show increasing levels of total and pMK2 protein beginning $3 \mathrm{~d}$ after injury, reaching a peak by day 7. B, Quantification of pMK2 from Western blots. The values show fold increase relative $\beta$-actin ${ }^{*} p<0.05 ; n=4$; see supplemental Fig. 7 , available at www.jneurosci.org as supplemental material for comparison with total MK2). $(-J$, Representative micrographs of immunofluorescence labeling of spinal cord sections $12 \mathrm{~h}(\boldsymbol{C}, \boldsymbol{F})$ and $7 \mathrm{~d}(\boldsymbol{D}, \boldsymbol{G}, \boldsymbol{I}, \boldsymbol{J})$ after $S \mathrm{Cl}$ labeled for pMK2, cell type-specific antibodies, and DAPI staining (merged images). $\boldsymbol{C}, \boldsymbol{D}$, Double labeling with anti-pMK2 and anti-NeuN for neurons at $500 \mu$ m caudal to epicenter. $\boldsymbol{F}, \mathbf{G}$, Double labeling for anti-pMK2 and anti-GFAP for astrocytes at $500 \mu \mathrm{m}$ caudal to epicenter. $I, J$, Double labeling for pMK2 and anti-Mac- 1 for macrophages at epicenter of injury $(I)$ and microglia $(J)$ at $500 \mu \mathrm{m}$ caudal to epicenter. Arrows point to pMK2-immunopositive cells and insets in panels show higher-magnification images of pMK2 ${ }^{+}$cells from the boxed areas. Note that pMK2 labeling is localized primarily to the nuclei of macrophages/microglia, which are double-labeled with Mac-1, a cell surface label. As a result, the two labels are not superimposed but the staining nevertheless shows colabeling of the same cell. Quantitative analysis of pMK2 ${ }^{+}$ neurons $(\boldsymbol{E})$ and astrocytes $(\boldsymbol{H})$ at $12 \mathrm{~h}$ and $7 \mathrm{~d}$ after injury. $n=6$ per time point. Scale bar, $100 \mu \mathrm{m}$.

MAPK in mediating inflammation, we assessed the role of MK2 after spinal cord injury.

\section{Phospho-MK2 localization in the injured spinal cord}

We first examined the levels of total and phospho-MK2 (pMK2), at various times after spinal cord contusion injury ( $50 \mathrm{kdyn}$ force; 400-600 $\mu \mathrm{m}$ tissue displacement). The pMK2 levels increased after injury, reached maximal expression by day 7 ( $p<0.05, t$ test; $n=4$ ) (Fig. 1A,B). Total MK2 showed similar changes, reaching peak levels at $7 \mathrm{~d}$, decreasing thereafter but remaining elevated above control levels at $28 \mathrm{~d}$ postinjury (Fig. $1 \mathrm{~A}$ ). The increase in pMK2 and MK2 expression mirrors closely the entry of immune cells and the activation of microglia/macrophages in the injured spinal cord. We next examined the cell types expressing pMK 2 at $12 \mathrm{~h}$ and $7 \mathrm{~d}$ after SCI. These times correspond to the peak of proinflammatory chemokine/cytokine production (12 h) (Bartholdi and Schwab, 1997; McTigue et al., 1998; Yang et al., 2004; Pineau and Lacroix, 2007) and the peak of macrophage numbers (7 d) (Sroga et al., 2003; Kigerl et al., 2006) in the injured spinal cord.
Double-immunofluorescence labeling with anti-pMK2 and cell type-specific antibodies showed that, at $12 \mathrm{~h}, \mathrm{pMK} 2 \mathrm{ap}-$ pears to be found primarily in neurons $\left(19.8 \%\right.$ of $\mathrm{NeuN}^{+}$cells) and astrocytes $\left(66.3 \%\right.$ of $\mathrm{GFAP}^{+}$cells) (Fig. $\left.1 C, E, F, H\right)$. At $7 \mathrm{~d}$ postinjury, the number of $\mathrm{pMK} 2^{+}$ neurons increased by $55 \%$, while the number of $\mathrm{pMK} 2{ }^{+}$astrocytes decreased by $88 \%$ compared with $12 \mathrm{~h}$ after SCI (Fig. $1 D, E, G, H)$. Microglia did not appear to express pMK 2 at $12 \mathrm{~h}$ after injury (supplemental Fig. 2, available at www.jneurosci. org as supplemental material), while at $7 \mathrm{~d}$ after SCI, which is the peak of the macrophage response after SCI (Sroga et al., 2003; Kigerl et al., 2006), 45.2\% of the Mac- $1^{+}$macrophage/microglia appeared to show pMK2 immunoreactivity (Fig. $1 I, J)$. In contrast, very few oligodendrocytes showed immunoreactivity for pMK2 $\left(2.9 \%\right.$ of $\mathrm{CC}^{+}{ }^{+}$cells $)$in the injured spinal cord. Neutrophils did not express pMK2 at either time point examined. Little if any pMK2 labeling was detected in the naive, injured spinal cord (supplemental Fig. 3, available at www.jneurosci. org as supplemental material). Preliminary Western blotting showed no change in pMK2 expression at $12 \mathrm{~h}$ relative to laminectomized spinal cord (data not shown). On the other hand, immunofluorescence analysis showed increased immunoreactivity in neurons and astrocytes at this time point, suggesting reduced sensitivity at the Western blot level.

\section{Locomotor recovery is significantly improved in $M K 2^{-1-}$ mice}

We next assessed the effect of MK2 on locomotor recovery after spinal cord contusion injury using $M K 2$ knock-out and wild-type mice. Genotyping and Western blotting were done to ensure the lack of MK2 expression in the knock-out mice (supplemental Fig. 4, available at www.jneurosci. org as supplemental material). Locomotor recovery was evaluated using the 9-point BMS (Basso et al., 2006) in replicate studies, with the scores pooled. All mice had normal locomotor function before injury ( $9 / 9$ score and $11 / 11$ subscore). There is a significant improvement in locomotor recovery in $\mathrm{MK} 2^{-1-}$ mice starting at $5 \mathrm{~d}$ postinjury (Fig. $2 A ;{ }^{\star} p<0.05$ ). Two-way repeatedmeasures ANOVA shows a significant effect between the two genotypes over time ( $p=0.002$ for BMS score; and $p<0.001$ for BMS subscore). Post hoc analysis revealed significant differences between the two strains in the BMS score starting at day 5 and lasting until the completion of the study at day 28 (Fig. 2A; ${ }^{*} p<0.05$; two-way RM-ANOVA, post hoc Tukey test). One day after injury, wild-type and MK2-null mice both exhibited severe hindlimb paralysis with little, if any, hindlimb movement (BMS scores $=0.23$ and 0.30, respectively). By day 28, wild-type mice had a BMS score of $5.50 \pm 0.36$ while $M K 2^{-1-}$ mice had a BMS score of 7.65 \pm 0.32 . Differences in locomotor control were further evident in the BMS subscores, which as- 


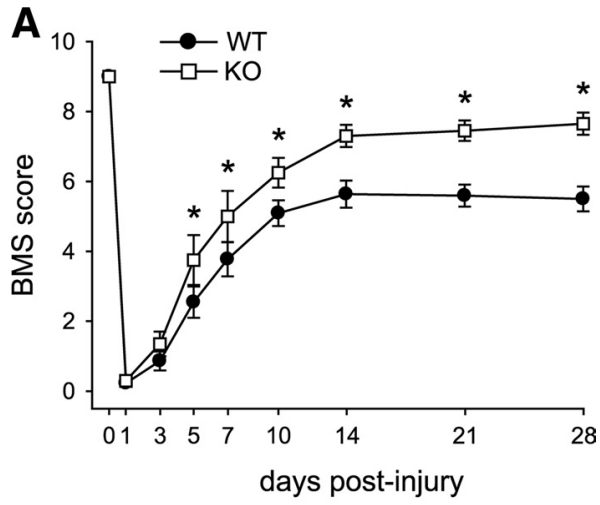

B

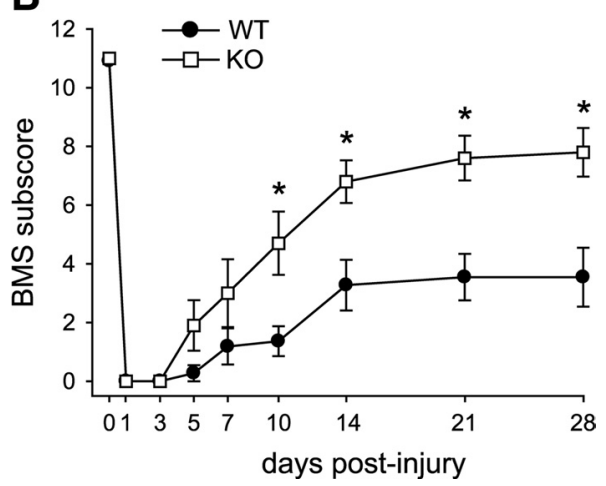

Figure 2. $\quad A, M K 2^{-1-}$ mice show significant improvement in locomotor recovery, assessed using BMS analysis, compared with wild-type mice starting as early as $5 \mathrm{~d}$ after injury and improving even further during the $28 \mathrm{~d}$ duration of the study. $\boldsymbol{B}$, The BMS subscores, which measure finer aspects of locomotor control, also show marked improvement in $M K 2^{-1-}$ mice between days 10 and 28 after $S C l .{ }^{*} p<0.05 ; n=10-11$ per group.

sess finer aspects of locomotor control. Significant improvement in BMS subscores was seen in MK2-null mice from day 10 to day 28 after SCI (Fig. $2 B$ ). At $28 \mathrm{~d}$ postinjury, $M K 2^{-1-}$ mice had a mean subscore that was 4.25 points higher than wild-type mice $\left({ }^{*} p<0.001\right.$; two-way RM-ANOVA, post hoc Tukey test).

\section{Reduced secondary damage after SCI in $M K 2^{-1-}$ mice}

We next assessed the histological differences in the spinal cord tissue that may account for the improved locomotor recovery after SCI in $M K 2^{-1-}$ mice. These included neuron loss, myelin loss, and sparing of serotonergic innervation in the ventral horn caudal to the injury epicenter at $28 \mathrm{~d}$ after SCI. The survival of ventral horn neurons, which play an important role in locomotor function, is significantly greater in $M K 2^{-1-}$ mice relative to wildtype controls (Fig. $3 A-C$; $p=0.012$ between groups, two-way RMANOVA). Post hoc analysis revealed significant differences between the two strains at $400-1000 \mu \mathrm{m}$ caudally and $1000 \mu \mathrm{m}$ rostrally compared with wild-type controls (Fig. $3 A ;{ }^{\star} p<0.05$, two-way RMANOVA, post hoc Tukey test). The average of these values over the 2 $\mathrm{mm}$ distance is also significantly different (wild-type $=408 \pm 31 \mathrm{vs}$ knock-out $=535 \pm 32 ; p=0.011 ; t$ test). Myelin loss, another marker of secondary damage, was measured using LFB. This was quantified in the region of the dorsal column, which shows the maximum amount of white matter damage because of the direct impact of the contusion force. Based on the area of LFB staining, there was increased sparing of myelin in the dorsal column of $M K 2$ knock-out mice, compared with wild-type mice (Fig. 3D-F; $p=0.029$ between groups, two-way RM-ANOVA). Post hoc analysis revealed signifi- cant differences at 600 and $400 \mu \mathrm{m}$ rostral, and $600 \mu \mathrm{m}$ caudal to the injury epicenter (Fig. 3D; ${ }^{\star} p<0.05$, two-way RM-ANOVA, post hoc Tukey test). These differences are unlikely to be due to differences in oligodendrocyte apoptosis as very few oligodendrocytes expressed pMK2 after SCI as mentioned above. Moreover, myelination is unaffected in the uninjured CNS and peripheral nerve of $M K 2^{-1-}$ mice (data not shown). These results indicate that a lack of $\mathrm{MK} 2$ reduces secondary tissue damage in the spinal cord after contusion injury in mice.

In addition, the density of serotonergic innervation $1 \mathrm{~mm}$ caudal to the injury site was also examined as this descending serotonergic input from the raphe nuclei in the brainstem is thought to be important for locomotor control (Ribotta et al., 2000; Antri et al., 2002; Oatway et al., 2005). This analysis revealed significantly greater sparing of serotonergic fibers caudal to the injury site ( $p=0.002, t$ test $)$ in $M K 2^{-1-}$ mice, relative to wild-type controls (Fig. 3G-I).

\section{Reduced proinflammatory cytokine levels and neutrophil influx in $M K 2^{-1-}$ mice}

We examined the expression of chemokines and cytokines using a bead-based Multiplex cytokine protein assay at $12 \mathrm{~h}$ after SCI. This time point was chosen because increased expression of chemokines and cytokines occurs within the first $24 \mathrm{~h}$ after SCI (Yang et al., 2004; Pineau and Lacroix, 2007). Mice lacking MK2 showed a marked reduction in the expression of several cytokines, relative to wild-type controls (Table 3). Tumor necrosis factor $\alpha$ (TNF- $\alpha$ ) showed a striking 26.5-fold reduction, while CCL3/MIP- $1 \alpha$ showed a 10.4 -fold reduction in the injured spinal cord of MK2-null mice relative to injured wild-type mice. In addition, basic fibroblast growth factor and interleukin-12 (IL12) levels were reduced 2.1-fold and 2.6-fold, respectively in tissue from MK2-null mice. For reasons that are not clear at present, IL-5 and CCL2/MCP-1 [chemokine (C-C motif) ligand 3/monocyte chemotactic protein-1] showed increases in MK2-null mice of 2.4-fold and 2.7-fold, respectively.

As the cytokines reduced in $M K 2^{-1-}$ mice have been implicated in mediating neutrophil entry into the CNS, we next examined the influx of neutrophils into the spinal cord of $M K 2^{-1-}$ and wild-type mice $12 \mathrm{~h}$ after injury because the peak of neutrophil influx into the spinal cord occurs early after injury (Donnelly and Popovich, 2008; Stirling and Yong, 2008). Interestingly, there were very few, if any, neutrophils present in the spinal cords of $M K 2^{-1-}$ mice at this time $(1.0 \pm 0.44)$, while neutrophils were found in significant numbers throughout the injured spinal cord tissue of wild-type mice $(12.1 \pm 0.9 ; p<0.001 ; t$ test; $n=9)$. Those that were present in the CNS of $M K 2$ knock-out mice were found near blood vessels or the meninges. In contrast to the reduction in neutrophils, there were no differences in the density or numbers of macrophages in the spinal cords of $M K 2^{-1-}$ mice, compared with wild-type controls, at $7 \mathrm{~d}$ after injury (data not shown).

\section{Changes in Hsp25 phosphorylation and other markers of secondary damage in $M K 2^{-I-}$ mice}

The phosphorylation of heat shock protein 25 (Hsp25), which is a direct substrate of MK2, has been shown to alter chemokine/ cytokine, MMP and complement production (Hansen et al., 2001; Rousseau et al., 2006). Hsp25 expression was therefore assessed $7 \mathrm{~d}$ after SCI because at the Western blot level the maximum expression of MK2 was at day 7. Western blot analysis of the spinal cord at $7 \mathrm{~d}$ after SCI showed no change in levels of total Hsp25 between the two strains of mice (Fig. $4 A, C$ ), but there was a marked 

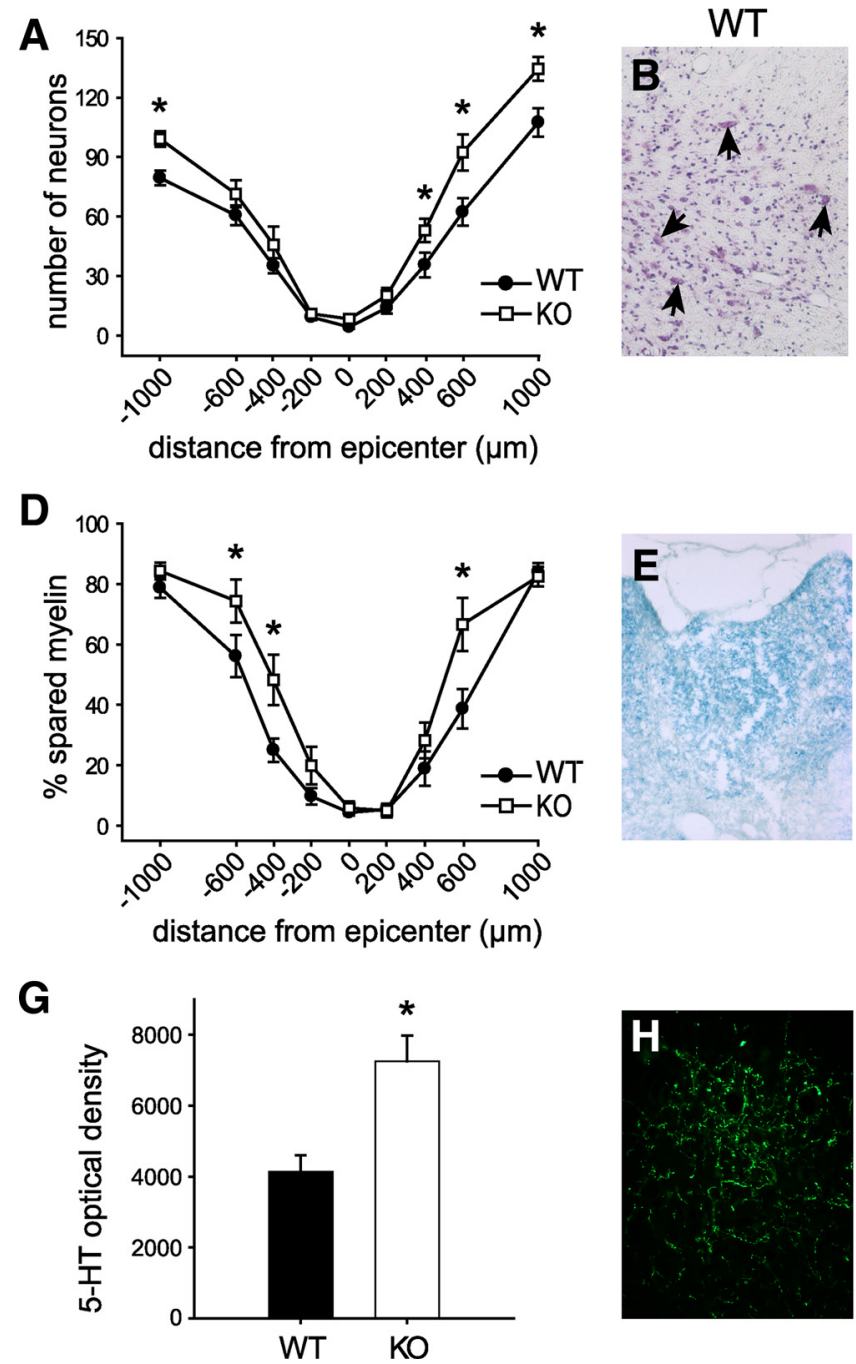

Figure 3. A, Quantification of ventral horn neuron survival at various distances rostral and caudal to the injury epicenter (0) reveals significantly greater neuronal survival in $\mathrm{MK2}^{-1-}$ mice, relative to wild-type animals, taken $28 \mathrm{~d}$ after $\mathrm{SCl} . \boldsymbol{B}$, $\boldsymbol{C}$, Representative micrographs showing sparing of ventral horn neurons in wild-type $(\boldsymbol{B})$ and $M K 2^{-1-}(\boldsymbol{C})$ mice in tissue sections stained with cresyl violet at $500 \mu \mathrm{m}$ caudal to the injury epicenter; arrows point to surviving neurons. $\boldsymbol{D}$, Quantification of myelin sparing in the dorsal column in serial tissue sections stained with Luxol Fast Blue rostral and caudal to the lesion epicenter. Note the significantly greater spared myelin in $M K 2^{-1-}$ mice relative to wild-type animals. $\boldsymbol{E}, \boldsymbol{F}$, Representative micrographs showing LFB staining of tissue sections from wild-type $(\boldsymbol{E})$ and $M K 2^{-1-}(\boldsymbol{F})$ mice. $\boldsymbol{G}$, Optical density measurements of serotonergic (5-HT) immunoreactivity indicate that $M K 2^{-1-}$ mice show an almost twofold increase in $5-\mathrm{HT}$ innervation of the ventral horn $1 \mathrm{~mm}$ caudal to the lesion epicenter compared with wild-type animals. $\boldsymbol{H}$, $\boldsymbol{I}$, Representative micrographs showing 5 -HT immunoreactivity in the ventral horn of the spinal cord from wild-type $(\boldsymbol{H})$ and $M K 2^{-I-}(I)$ mice. ${ }^{*} p<0.05 ; n=9-11$ per group; Scale bar, $200 \mu \mathrm{m}$.

reduction in the level of phospho-Hsp25 in $M K 2$-deficient mice, relative to wild-type controls (Fig. $4 B, C$; ${ }^{\star} p<0.05$; $t$ test). In contrast, both total and phosphorylated levels of p38 MAPK, which is upstream of and stabilized by MK2, are reduced in $M K 2^{-1-}$ mice (data not shown), as has previously been reported (Kotlyarov et al., 2002).

Peroxynitrite, a highly reactive oxygen species, is formed by NO and leads to the nitration of tyrosine residues in proteins to form 3-nitrotyrosine (3-NT). This stable product is a hallmark of secondary damage and oxidative stress after SCI with elevated levels present at $7 \mathrm{~d}$ (Liu et al., 2000; Xiong et al., 2007), corresponding with the peak macrophage response and pMK2 levels after SCI. Immunostaining of the spinal cord at $7 \mathrm{~d}$ after SCI revealed $\sim 40 \%$ reduction in 3-NT levels in $M K 2^{-I-}$ mice (Fig. $4 D$; ${ }^{\star} p<0.05$; $t$ test; supplemental Fig. 5, available at www.jneurosci.org as supplemental mate-
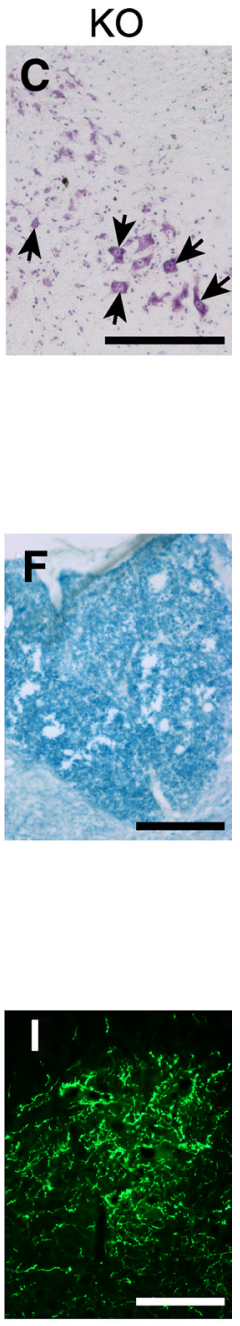

rial). Matrix metalloproteinases have also been shown to play important roles in SCI. MMP-2 and MMP-9 in particular have been well characterized and shown to have antagonistic effects on outcome after SCI. MMP-2 activity is increased during wound healing and angiogenesis (Hsu et al., 2006). Conversely, MMP-9 is thought to be detrimental to recovery as it disrupts the bloodbrain barrier, allowing for the increased influx of inflammatory cells (Noble et al., 2002), leading to increased secondary tissue damage. We therefore assessed MMP-2 and -9 activities in the injured spinal cord by gelatin zymography at $7 \mathrm{~d}$ after SCI, the peak of the macrophage response and pMK2 protein levels (Fig. 4E). This time point was chosen for analysis because previous work has shown that MMP-2 is not expressed before $3 \mathrm{~d}$ and both MMPs are expressed in the injured spinal cord at $7 \mathrm{~d}$ after SCI (Goussev et al., 2003; Hsu et al., 2008). This analysis showed a $46 \%$ reduction in MMP-9 activity in 2 of $3 \mathrm{MK}^{-1-}$ mice and a $48 \%$ increase in MMP-2 activity in 3 of $3 \mathrm{MK}^{-/-}$mice examined ( $p=0.035 ; t$ test).

\section{Macrophages lacking MK2 retain their capacity to phagocytose myelin}

Previous work from our group and others has shown that activated $\mathrm{MK} 2^{-1-}$ macrophages show reduced expression of proinflammatory cytokines and nitric oxide in vitro (Lehner et al., 2002; Thuraisingam et al., 2007). We therefore assessed whether these macrophages still retain their capacity to phagocytose myelin. Wild-type and MK2-null macrophage cell lines were cultured in 24-well plates and incubated with fluorescent DiI-labeled myelin. FACS analysis of these cells $1 \mathrm{~h}$ after the addition of myelin revealed a $\sim 25 \%$ reduction in the number of phagocytic MK2-deficient macrophages, relative to control cells (Fig. $5 A$; supplemental Fig. 6, available at www. jneurosci.org as supplemental material). However, the average fluorescence intensity of phagocytosed myelin per macrophage was similar between the two cell lines (Fig. 5B). This suggests that while the percentage of phagocytic macrophages is slightly reduced in the absence of MK2, the ability of these cells to phagocytose myelin remains unaltered.

\section{Discussion}

We studied the effects of the expression of MK2, one of the downstream targets of p38 MAPK that can regulate proinflammatory function after spinal cord injury. We found increased pMK2 early after SCI in neurons and astrocytes, and later in microglia/macrophages. To understand the effects of MK2 after SCI, we used MK2-null mice and show that there is marked improvement in locomotor recovery; significant reduction in neuronal and myelin loss, and of protein nitrosylation; reduction of phosphorylation of Hsp25 and expression of proinflammatory cytokines/ 
Table 3. Results from multiplex analysis of cytokine and chemokine protein profiles from wild-type and $M K 2^{-/-}$mice $12 \mathrm{~h}$ after spinal cord injury listed alphabetically

\begin{tabular}{lccc}
\hline Cytokine & Wild type $(\mathrm{pg} / \mathrm{ml})$ & Knock-out $(\mathrm{pg} / \mathrm{ml})$ & $p$ value \\
\hline$\downarrow_{\text {FGF basic }}$ & $4050 \pm 790$ & $1919 \pm 201$ & 0.038 \\
GM-CSF & $18 \pm 7$ & $13 \pm 2$ & 0.301 \\
IFN- $\gamma$ & $91 \pm 11$ & $106 \pm 6$ & 0.139 \\
IL-1 $\alpha$ & $77 \pm 20$ & $139 \pm 41$ & 0.151 \\
IL-1 $\beta$ & $47 \pm 6$ & $33 \pm 9$ & 0.145 \\
IL-2 & $18 \pm 1$ & $16 \pm 1$ & 0.239 \\
IL-4 & $60 \pm 7$ & $54 \pm 8$ & 0.482 \\
$\uparrow_{\text {IL-5 }}$ & $111 \pm 3$ & $262 \pm 46$ & 0.021 \\
IL-6 & $502 \pm 313$ & $801 \pm 377$ & 0.426 \\
IL-10 & $347 \pm 68$ & $296 \pm 8$ & 0.257 \\
$\downarrow$ IL-12 & $340 \pm 86$ & $132 \pm 33$ & 0.028 \\
IL-13 & $31 \pm 0$ & $31 \pm 3$ & 0.789 \\
IL-17 & $11 \pm 0$ & $13 \pm 3$ & 0.326 \\
IP-10 & $530 \pm 16$ & $383 \pm 137$ & 0.247 \\
KC & $1497 \pm 458$ & $1611 \pm 286$ & 0.747 \\
${ }^{\text {CCCL2/MCP-1 }}$ & $722 \pm 120$ & $1925 \pm 376$ & 0.025 \\
MIG & $33 \pm 6$ & $33 \pm 2$ & 0.859 \\
$\downarrow_{\text {CCL3/MIP- } 1} \alpha$ & $4935 \pm 690$ & $474 \pm 173$ & 0.001 \\
$\downarrow_{\text {TNF- } \alpha} \alpha$ & $1694 \pm 972$ & $64 \pm 5$ & 0.049 \\
VEGF & $108 \pm 41$ & $89 \pm 17$ & 0.508 \\
\hline
\end{tabular}

Values represent mean \pm SD. $\downarrow$ indicates cytokines that decreased and $\uparrow$ indicates cytokines that increased expression in MK2 ${ }^{-1-}$ mice. FGF, Fibroblastic growth factor; GM-CSF, granulocyte macrophage colony-stimulating factor; IFN- $\gamma$, interferon- $\gamma$; IP-10, interferon- $\gamma$-induced protein $10 \mathrm{kDa}$; MIG, monokine induced by IFN- $\gamma$; VEGF, vascular endothelial growth factor.
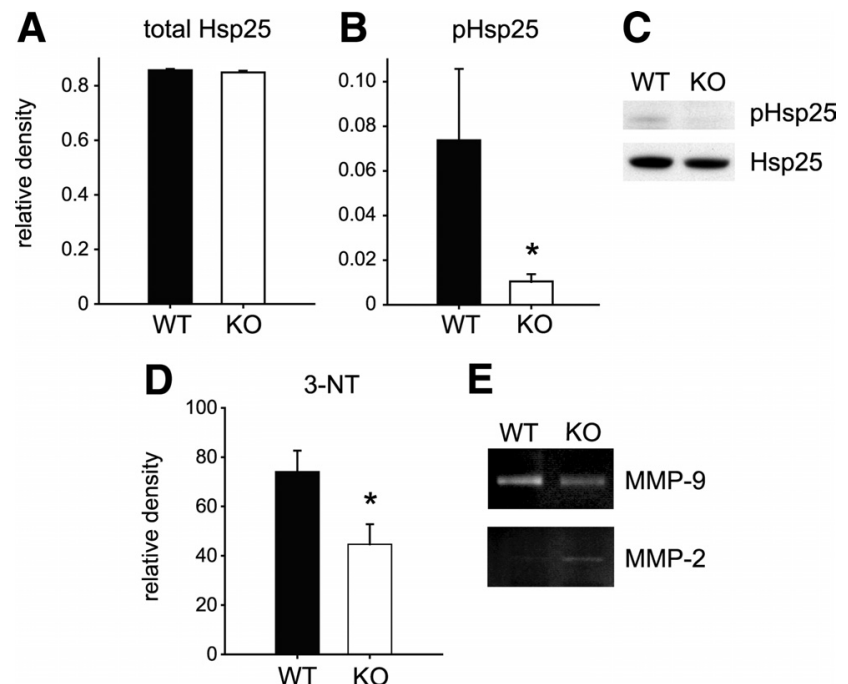

E

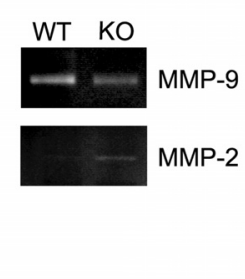

Figure 4. $\quad \boldsymbol{A}, \boldsymbol{B}$, Densitometric values of Western blots for total $H \mathrm{sp} 25(\boldsymbol{A})$ and phosphorylated Hsp25 (B) in spinal cord tissue $7 \mathrm{~d}$ after SCl, each normalized to $\beta$-actin. Note the significant reduction in pHsp25 levels in MK2 ${ }^{-1-}$ mice [KO (knockout)] compared with wild-type mice (WT), but no change in total Hsp25 levels between the two strains ( $n=3$ per group). $C$, Western blots showing pHSP25 and total HSP25. D, Quantification of 3-nitrotyrosine (3-NT) levels in the lateral funiculus $7 \mathrm{~d}$ after $\mathrm{SCl}$, measured by optical density reading of tissue sections, reveals significantly reduced protein nitration in MK2-null mice relative to wild-type animals $(n=10$ per group). Similar results were also seen in the dorsal column. $\boldsymbol{E}$, Representative examples of gelatin zymography showing reduced MMP-9 and increased MMP-2 in spinal cord tissue of $M K 2^{-I-}$ (KO) and WT mice at $7 \mathrm{~d}$ after $\mathrm{SCl}\left(n=4\right.$ per group). ${ }^{*} p<0.05$.

chemokines; reduced infiltration of neutrophils into the injured spinal cord; and reduced MMP-9 and increased MMP-2 activity in the $M K 2^{-1-}$ mice relative to injured wild-type mice. Using macrophage cell lines we also show that myelin phagocytosis is relatively unaltered in $M K 2$-deficient cells.

Previous studies have reported increased levels of p38 MAPK after spinal cord injury (Horiuchi et al., 2003; Yune et al., 2003; Z.
A

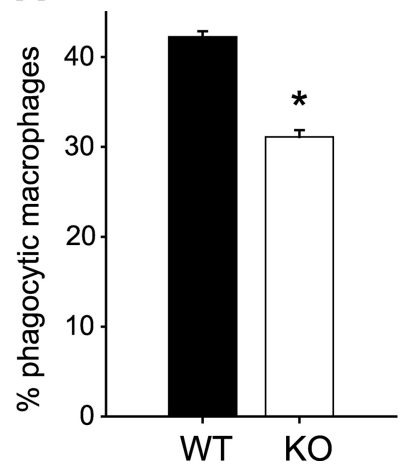

B

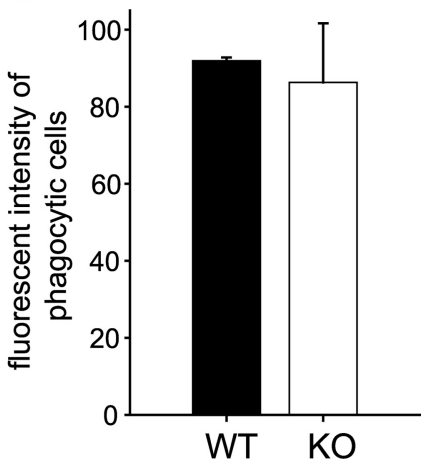

Figure 5. $M K 2^{-1-}$ macrophages retain their ability to phagocytose myelin. MK2 knock-out (KO) and wild-type (WT) macrophage cell lines were incubated with or without fluorescent Dil-labeled myelin in vitro for 30 min and analyzed by FACS to measure myelin phagocytosis. $\boldsymbol{A}$ FACS data show a $25 \%$ reduction in the number of $M K 2^{-1-}$ macrophages that phagocytose myelin compared with wild-type macrophages. $\boldsymbol{B}$, For the $75 \%$ of cells that phagocytose myelin, there is no difference in the mean fluorescence intensity of the cells, indicating that these $M K 2^{-1-}$ macrophages are able to phagocytose myelin as effectively as wild-type macrophages. ${ }^{*} p<0.05 ; n=3$ per group.

Xu et al., 2006). Based on these results and the work of others showing that MK2, a direct substrate for p38 MAPK, can mediate cytotoxic effects after injury or disease (Wang et al., 2002; Culbert et al., 2006; L. Xu et al., 2006; Thuraisingam et al., 2007; Thomas et al., 2008), we analyzed pMK2 levels after SCI. We see that as early as $12 \mathrm{~h}$ after SCI, pMK2 is expressed in neurons and astrocytes. This is interesting because neurons and CNS glia have been shown to express proinflammatory cytokines within hours after SCI (Yang et al., 2004; Pineau and Lacroix, 2007). The robust expression of these cytokines by neurons suggests that they may be one of the first responders to CNS injury that triggers subsequent immune cell infiltration and inflammation (Liu et al., 1994; de Rivero Vaccari et al., 2008). The marked reduction of TNF- $\alpha$ and CCL3/MIP- $1 \alpha$ in the injured spinal cord of MK2-null mice at this early time point after SCI suggests that pMK2 in neurons and glia may play a role in the early phase of triggering injury-induced inflammation. Seven days after SCI, pMK2 expression is seen primarily in macrophages/microglia, neurons, and some astrocytes. MK2 has previously been shown to play an important role in regulating proinflammatory chemokine and cytokine expression in macrophages in vitro (Culbert et al., 2006; Thuraisingam et al., 2007). This effect may be mediated by MK2dependent phosphorylation of proteins binding to AU-rich elements in the $3^{\prime}$ untranslated region (UTR) of cytokine mRNAs, such as TTP (Mahtani et al., 2001; Chrestensen et al., 2004), which stabilizes the transcript and allows for efficient translation of the protein, leading to the increased production of proinflammatory cytokines, including TNF- $\alpha$ (Winzen et al., 1999; Mahtani et al., 2001; Neininger et al., 2002). MK2 can also phosphorylate Hsp25, which can also affect cytokine production (Stokoe et al., 1992; Lopes et al., 2009). Reduced binding of phosphorylated TTP to UTRs results in stabilization of the mRNA and increased cytokine production (Hitti et al., 2006), while phosphorylation of Hsp 25 regulates mRNA stability by increasing p 38 MAPK activation (Alford et al., 2007). Although the mechanism of its actions are still unknown, it has been suggested that phosphorylation of Hsp25, which causes the dissociation of its multimeric form, may activate its chaperone function (Alford et al., 2007; Hayes et al., 2009). Our results show reduced phosphorylation of Hsp25 and reduced expression of proinflammatory cy- 
tokines (TNF- $\alpha$, IL-12 and CCL3/MIP- $1 \alpha$ ) in the spinal cords of $M K 2^{-1-}$ mice after SCI. The latter effect may underlie the marked reduction in neutrophil influx into the spinal cord of MK2-null mice at $12 \mathrm{~h}$ after contusion injury, as TNF- $\alpha$, IL-12 and CCL3/MIP- $1 \alpha$ have previously been shown to stimulate neutrophil recruitment and activation (Lukacs et al., 1995; Ramos et al., 2005; Moreno et al., 2006). These observations are of relevance since several studies suggest that neutrophils may to contribute to secondary damage in SCI (Taoka et al., 1997; Tonai et al., 2001; Gris et al., 2004), although a recent study with neutrophil depletion showed contrary results (Stirling et al., 2009).

Our previous work has shown that a macrophage cell line lacking MK2 fails to upregulate the expression of TNF- $\alpha$ and NO in response to LPS activation (Thuraisingam et al., 2007). SCI in $M K 2^{-1-}$ mice results not only in reduced production of detrimental proinflammatory cytokines, but also of 3-NT and MMP-9 activity, with a simultaneous increase in the protective MMP-2. These changes are accompanied by increased neuronal survival and greater sparing of myelin and serotonergic axons in MK2null mice, which may contribute to the better locomotor recovery seen in these mice. Previous studies have also shown that activated $M K 2^{-1-}$ microglia and macrophages are less neurotoxic when cultured with either wild-type (Culbert et al., 2006) or $M K 2^{-1-}$ neurons (Thomas et al., 2008). This was thought to be a result of the reduced inflammatory response and not because of a direct role for MK2 in mediating neuronal death (Thomas et al., 2008). Therefore, some of the protective effects observed in our SCI study may be due at least in part to a reduced proinflammatory response in $M K 2^{-1-}$ microglia/macrophages. While diminished phagocytic activity has been observed in $\mathrm{MK}^{-1-}$ macrophages in response to bacteria or lipoproteins (Lehner et al., 2002; Jagavelu et al., 2007), our results point to no change in the phagocytic activity of the macrophages that are capable of myelin phagocytosis in vitro. Interestingly, minocycline, which has been shown to have neuroprotective effects after SCI (Wells et al., 2003a; Stirling et al., 2004) can also reduce MK2 and p38 phosphorylation after SCI (Yune et al., 2007).

Another finding is the altered expression of MMPs after SCI in $M K 2^{-1-}$ mice. Gelatin zymograms of spinal cord homogenates taken $7 \mathrm{~d}$ after injury show a decrease in MMP-9 and a concomitant increase in MMP-2 activity in the injured spinal cord of in $M K 2^{-1-}$ mice. Spinal cord injury in mice lacking these two MMPs has revealed contrasting roles for them in tissue repair responses and recovery of function. MMP-9 activity, found in macrophages, astrocytes and blood vessels after SCI, contributes to the breakdown of the blood-brain barrier and an increased inflammatory response (Noble et al., 2002), while MMP-2, produced by astrocytes, facilitates white matter sparing (Hsu et al., 2006). Therefore, deficiency in MMP-9 is beneficial to histological and locomotor outcomes, while MMP-2 deficiency is detrimental to recovery. Inhibition of $\mathrm{p} 38 \mathrm{MAPK}$ has also been shown to result in reduced levels of MMP-9 (Underwood et al., 2000). The differential regulation of these two MMPs has been shown in vitro when $\mathrm{NAD}(\mathrm{P}) \mathrm{H}$ is inhibited after treatment of myocardial cells with doxorubicin, an anti-tumor agent (Spallarossa et al., 2006). Inhibition of $\mathrm{NAD}(\mathrm{P}) \mathrm{H}$ redox activity leads to increased MMP-9 (via p38 MAPK and JNK) and reduced MMP-2 (via ERK 1/2). What effect MK2 deficiency may have on other MMPs implicated in SCI (Wells et al., 2003b; Yong et al., 2007) remains unknown.

Together, the results obtained in the present study, and other work done on $M K 2^{-1-}$ macrophages (Thuraisingam et al., 2007), show that the lack of MK2 changes the phenotype of macrophages to one that produces less proinflammatory cytokines and mediators of oxidative stress, while retaining their ability to phagocytose myelin and possibly other tissue debris. Such a change in phenotype resulting from the lack of MK2 may contribute to the reduced secondary damage and enhanced locomotor recovery after SCI. Recent work by Kigerl and colleagues points to a heterogeneous macrophage population in the spinal cord after injury - a proinflammatory/cytotoxic M1 macrophage response and a potentially proregenerative/noncytotoxic M2 macrophage response (Kigerl et al., 2009). Our data suggest that MK2 plays multiple roles that are detrimental to the repair process after SCI. Whether the macrophages present in the spinal cord of $\mathrm{MK} 2^{-1-}$ mice possess a more prominent M2 phenotype is currently under investigation. The increased sparing of tissue and reduced proinflammatory cytokine profiles would, however, suggest that this may be the case. As our data suggest that MK2 plays multiple roles detrimental to the repair process after SCI, the use of selective pharmacological inhibitors of MK2 would therefore be a useful therapeutic tool for the treatment of acute spinal cord injury.

\section{References}

Alford KA, Glennie S, Turrell BR, Rawlinson L, Saklatvala J, Dean JL (2007) Heat shock protein 27 functions in inflammatory gene expression and transforming growth factor-beta-activated kinase-1 (TAK1)-mediated signaling. J Biol Chem 282:6232-6241.

Al-Shahrour F, Minguez P, Vaquerizas JM, Conde L, Dopazo J (2005) BABELOMICS: a suite of web tools for functional annotation and analysis of groups of genes in high-throughput experiments. Nucleic Acids Res 33:W460-464.

Antri M, Orsal D, Barthe JY (2002) Locomotor recovery in the chronic spinal rat: effects of long-term treatment with a 5-HT2 agonist. Eur J Neurosci 16:467-476.

Bao F, Chen Y, Dekaban GA, Weaver LC (2004) Early anti-inflammatory treatment reduces lipid peroxidation and protein nitration after spinal cord injury in rats. J Neurochem 88:1335-1344.

Bartholdi D, Schwab ME (1997) Expression of pro-inflammatory cytokine and chemokine mRNA upon experimental spinal cord injury in mouse: an in situ hybridization study. Eur J Neurosci 9:1422-1438.

Basso DM, Fisher LC, Anderson AJ, Jakeman LB, McTigue DM, Popovich PG (2006) Basso Mouse Scale for locomotion detects differences in recovery after spinal cord injury in five common mouse strains. J Neurotrauma 23:635-659.

Blight AR (1994) Effects of silica on the outcome from experimental spinal cord injury: implication of macrophages in secondary tissue damage. Neuroscience 60:263-273.

Chrestensen CA, Schroeder MJ, Shabanowitz J, Hunt DF, Pelo JW, Worthington MT, Sturgill TW (2004) MAPKAP kinase 2 phosphorylates tristetraprolin on in vivo sites including Ser178, a site required for 14-3-3 binding. J Biol Chem 279:10176-10184.

Crown ED, Gwak YS, Ye Z, Johnson KM, Hulsebosch CE (2008) Activation of p38 MAP kinase is involved in central neuropathic pain following spinal cord injury. Exp Neurol 213:257-267.

Culbert AA, Skaper SD, Howlett DR, Evans NA, Facci L, Soden PE, Seymour ZM, Guillot F, Gaestel M, Richardson JC (2006) MAPK-activated protein kinase 2 deficiency in microglia inhibits pro-inflammatory mediator release and resultant neurotoxicity. Relevance to neuroinflammation in a transgenic mouse model of Alzheimer disease. J Biol Chem 281:23658-23667.

de Rivero Vaccari JP, Lotocki G, Marcillo AE, Dietrich WD, Keane RW (2008) A molecular platform in neurons regulates inflammation after spinal cord injury. J Neurosci 28:3404-3414.

Donnelly DJ, Popovich PG (2008) Inflammation and its role in neuroprotection, axonal regeneration and functional recovery after spinal cord injury. Exp Neurol 209:378-388.

Erschbamer M, Pernold K, Olson L (2007) Inhibiting epidermal growth factor receptor improves structural, locomotor, sensory, and bladder recovery from experimental spinal cord injury. J Neurosci 27:6428-6435.

Gaestel M (2006) MAPKAP kinases - MKs - two's company, three's a crowd. Nat Rev Mol Cell Biol 7:120-130. 
Gaestel M, Kotlyarov A, Kracht M (2009) Targeting innate immunity protein kinase signalling in inflammation. Nat Rev Drug Discov 8:480-499.

Ghasemlou N, Kerr BJ, David S (2005) Tissue displacement and impact force are important contributors to outcome after spinal cord contusion injury. Exp Neurol 196:9-17.

Giulian D, Robertson C (1990) Inhibition of mononuclear phagocytes reduces ischemic injury in the spinal cord. Ann Neurol 27:33-42.

Goussev S, Hsu JY, Lin Y, Tjoa T, Maida N, Werb Z, Noble-Haeusslein LJ (2003) Differential temporal expression of matrix metalloproteinases after spinal cord injury: relationship to revascularization and wound healing. J Neurosurg 99:188-197.

Gris D, Marsh DR, Oatway MA, Chen Y, Hamilton EF, Dekaban GA, Weaver LC (2004) Transient blockade of the CD11d/CD18 integrin reduces secondary damage after spinal cord injury, improving sensory, autonomic, and motor function. J Neurosci 24:4043-4051.

Hamada Y, Ikata T, Katoh S, Katoh K, Niwa M, Tsutsumishita Y, Fukuzawa K (1996) Effects of exogenous transforming growth factor-beta 1 on spinal cord injury in rats. Neurosci Lett 203:97-100.

Hansen RK, Parra I, Hilsenbeck SG, Himelstein B, Fuqua SA (2001) Hsp27induced MMP-9 expression is influenced by the Src tyrosine protein kinase yes. Biochem Biophys Res Commun 282:186-193.

Hayes D, Napoli V, Mazurkie A, Stafford WF, Graceffa P (2009) Phosphorylation dependence of hsp27 multimeric size and molecular chaperone function. J Biol Chem 284:18801-18807.

Hitti E, Iakovleva T, Brook M, Deppenmeier S, Gruber AD, Radzioch D, Clark AR, Blackshear PJ, Kotlyarov A, Gaestel M (2006) Mitogenactivated protein kinase-activated protein kinase 2 regulates tumor necrosis factor mRNA stability and translation mainly by altering tristetraprolin expression, stability, and binding to adenine/uridine-rich element. Mol Cell Biol 26:2399-2407.

Horiuchi H, Ogata T, Morino T, Chuai M, Yamamoto H (2003) Continuous intrathecal infusion of SB203580, a selective inhibitor of p38 mitogenactivated protein kinase, reduces the damage of hind-limb function after thoracic spinal cord injury in rat. Neurosci Res 47:209-217.

Hsu JY, McKeon R, Goussev S, Werb Z, Lee JU, Trivedi A, Noble-Haeusslein LJ (2006) Matrix metalloproteinase-2 facilitates wound healing events that promote functional recovery after spinal cord injury. J Neurosci 26:9841-9850.

Hsu JY, Bourguignon LY, Adams CM, Peyrollier K, Zhang H, Fandel T, Cun CL, Werb Z, Noble-Haeusslein LJ (2008) Matrix metalloproteinase-9 facilitates glial scar formation in the injured spinal cord. J Neurosci 28:13467-13477.

Irizarry RA, Bolstad BM, Collin F, Cope LM, Hobbs B, Speed TP (2003) Summaries of Affymetrix GeneChip probe level data. Nucleic Acids Res 31:e15.

Jagavelu K, Tietge UJ, Gaestel M, Drexler H, Schieffer B, Bavendiek U (2007) Systemic deficiency of the MAP kinase-activated protein kinase 2 reduces atherosclerosis in hypercholesterolemic mice. Circ Res 101:1104-1112.

Jeong SY, David S (2003) Glycosylphosphatidylinositol-anchored ceruloplasmin is required for iron efflux from cells in the central nervous system. J Biol Chem 278:27144-27148.

Jin SX, Zhuang ZY, Woolf CJ, Ji RR (2003) p38 mitogen-activated protein kinase is activated after a spinal nerve ligation in spinal cord microglia and dorsal root ganglion neurons and contributes to the generation of neuropathic pain. J Neurosci 23:4017-4022.

Kanehisa M, Goto S (2000) KEGG: Kyoto encyclopedia of genes and genomes. Nucleic Acids Res 28:27-30.

Kigerl KA, McGaughy VM, Popovich PG (2006) Comparative analysis of lesion development and intraspinal inflammation in four strains of mice following spinal contusion injury. J Comp Neurol 494:578-594.

Kigerl KA, Gensel JC, Ankeny DP, Alexander JK, Donnelly DJ, Popovich PG (2009) Identification of two distinct macrophage subsets with divergent effects causing either neurotoxicity or regeneration in the injured mouse spinal cord. J Neurosci 29:13435-13444.

Kobayashi K, Yamanaka H, Fukuoka T, Dai Y, Obata K, Noguchi K (2008) P2Y12 receptor upregulation in activated microglia is a gateway of p38 signaling and neuropathic pain. J Neurosci 28:2892-2902.

Kotlyarov A, Neininger A, Schubert C, Eckert R, Birchmeier C, Volk HD, Gaestel M (1999) MAPKAP kinase 2 is essential for LPS-induced TNFalpha biosynthesis. Nat Cell Biol 1:94-97.

Kotlyarov A, Yannoni Y, Fritz S, Laass K, Telliez JB, Pitman D, Lin LL, Gaestel
M (2002) Distinct cellular functions of MK2. Mol Cell Biol 22:48274835.

Krens SF, Spaink HP, Snaar-Jagalska BE (2006) Functions of the MAPK family in vertebrate-development. FEBS Lett 580:4984-4990.

Kwon BK, Fisher CG, Dvorak MF, Tetzlaff W (2005) Strategies to promote neural repair and regeneration after spinal cord injury. Spine 30:S3-13.

Lehner MD, Schwoebel F, Kotlyarov A, Leist M, Gaestel M, Hartung T (2002) Mitogen-activated protein kinase-activated protein kinase 2-deficient mice show increased susceptibility to Listeria monocytogenes infection. J Immunol 168:4667-4673.

Liu D, Ling X, Wen J, Liu J (2000) The role of reactive nitrogen species in secondary spinal cord injury: formation of nitric oxide, peroxynitrite, and nitrated protein. J Neurochem 75:2144-2154.

Liu T, Clark RK, McDonnell PC, Young PR, White RF, Barone FC, Feuerstein GZ (1994) Tumor necrosis factor-alpha expression in ischemic neurons. Stroke 25:1481-1488.

Lopes LB, Flynn C, Komalavilas P, Panitch A, Brophy CM, Seal BL (2009) Inhibition of HSP27 phosphorylation by a cell-permeant MAPKAP kinase 2 inhibitor. Biochem Biophys Res Commun 382:535-539.

Lukacs NW, Strieter RM, Chensue SW, Widmer M, Kunkel SL (1995) TNFalpha mediates recruitment of neutrophils and eosinophils during airway inflammation. J Immunol 154:5411-5417.

Mahtani KR, Brook M, Dean JL, Sully G, Saklatvala J, Clark AR (2001) Mitogen-activated protein kinase p38 controls the expression and posttranslational modification of tristetraprolin, a regulator of tumor necrosis factor alpha mRNA stability. Mol Cell Biol 21:6461-6469.

McTigue DM, Tani M, Krivacic K, Chernosky A, Kelner GS, Maciejewski D, Maki R, Ransohoff RM, Stokes BT (1998) Selective chemokine mRNA accumulation in the rat spinal cord after contusion injury. J Neurosci Res 53:368-376.

Moreno SE, Alves-Filho JC, Alfaya TM, da Silva JS, Ferreira SH, Liew FY (2006) IL-12, but not IL-18, is critical to neutrophil activation and resistance to polymicrobial sepsis induced by cecal ligation and puncture. J Immunol 177:3218-3224.

Neininger A, Kontoyiannis D, Kotlyarov A, Winzen R, Eckert R, Volk HD, Holtmann H, Kollias G, Gaestel M (2002) MK2 targets AU-rich elements and regulates biosynthesis of tumor necrosis factor and interleukin- 6 independently at different post-transcriptional levels. J Biol Chem 277:30653068 .

Noble LJ, Donovan F, Igarashi T, Goussev S, Werb Z (2002) Matrix metalloproteinases limit functional recovery after spinal cord injury by modulation of early vascular events. J Neurosci 22:7526-7535.

Oatway MA, Chen Y, Bruce JC, Dekaban GA, Weaver LC (2005) AntiCD11d integrin antibody treatment restores normal serotonergic projections to the dorsal, intermediate, and ventral horns of the injured spinal cord. J Neurosci 25:637-647.

Peifer C, Wagner G, Laufer S (2006) New approaches to the treatment of inflammatory disorders small molecule inhibitors of p38 MAP kinase. Curr Top Med Chem 6:113-149.

Pineau I, Lacroix S (2007) Proinflammatory cytokine synthesis in the injured mouse spinal cord: multiphasic expression pattern and identification of the cell types involved. J Comp Neurol 500:267-285.

Popovich PG, Longbrake EE (2008) Can the immune system be harnessed to repair the CNS? Nat Rev Neurosci 9:481-493.

Popovich PG, Guan Z, Wei P, Huitinga I, van Rooijen N, Stokes BT (1999) Depletion of hematogenous macrophages promotes partial hindlimb recovery and neuroanatomical repair after experimental spinal cord injury. Exp Neurol 158:351-365.

Popovich PG, Guan Z, McGaughy V, Fisher L, Hickey WF, Basso DM (2002) The neuropathological and behavioral consequences of intraspinal microglial/macrophage activation. J Neuropathol Exp Neurol 61:623-633.

Ramos CD, Canetti C, Souto JT, Silva JS, Hogaboam CM, Ferreira SH, Cunha FQ (2005) MIP-1alpha[CCL3] acting on the CCR1 receptor mediates neutrophil migration in immune inflammation via sequential release of TNF-alpha and LTB4. J Leukoc Biol 78:167-177.

Rathore KI, Kerr BJ, Redensek A, López-Vales R, Jeong SY, Ponka P, David S (2008) Ceruloplasmin protects injured spinal cord from iron-mediated oxidative damage. J Neurosci 28:12736-12747.

Ribotta MG, Provencher J, Feraboli-Lohnherr D, Rossignol S, Privat A, Orsal D (2000) Activation of locomotion in adult chronic spinal rats is achieved by transplantation of embryonic raphe cells reinnervating a precise lumbar level. J Neurosci 20:5144-5152. 
Rice T, Larsen J, Rivest S, Yong VW (2007) Characterization of the early neuroinflammation after spinal cord injury in mice. J Neuropathol Exp Neurol 66:184-195.

Rousseau S, Dolado I, Beardmore V, Shpiro N, Marquez R, Nebreda AR, Arthur JS, Case LM, Tessier-Lavigne M, Gaestel M, Cuenda A, Cohen P (2006) CXCL12 and C5a trigger cell migration via a PAK1/2-p38alpha MAPK-MAPKAP-K2-HSP27 pathway. Cell Signal 18:1897-1905.

Roux PP, Blenis J (2004) ERK and p38 MAPK-activated protein kinases: a family of protein kinases with diverse biological functions. Microbiol Mol Biol Rev 68:320-344.

Saklatvala J (2004) The p38 MAP kinase pathway as a therapeutic target in inflammatory disease. Curr Opin Pharmacol 4:372-377.

Spallarossa P, Altieri P, Garibaldi S, Ghigliotti G, Barisione C, Manca V, Fabbi P, Ballestrero A, Brunelli C, Barsotti A (2006) Matrix metalloproteinase- 2 and -9 are induced differently by doxorubicin in $\mathrm{H} 9 \mathrm{c} 2$ cells: the role of MAP kinases and NAD(P)H oxidase. Cardiovasc Res 69:736-745.

Sroga JM, Jones TB, Kigerl KA, McGaughy VM, Popovich PG (2003) Rats and mice exhibit distinct inflammatory reactions after spinal cord injury. J Comp Neurol 462:223-240.

Stirling DP, Yong VW (2008) Dynamics of the inflammatory response after murine spinal cord injury revealed by flow cytometry. J Neurosci Res 86:1944-1958.

Stirling DP, Khodarahmi K, Liu J, McPhail LT, McBride CB, Steeves JD, Ramer MS, Tetzlaff W (2004) Minocycline treatment reduces delayed oligodendrocyte death, attenuates axonal dieback, and improves functional outcome after spinal cord injury. J Neurosci 24:2182-2190.

Stirling DP, Liu J, Plunet W, Steeves JD, Tetzlaff W (2008) SB203580, a p38 mitogen-activated protein kinase inhibitor, fails to improve functional outcome following a moderate spinal cord injury in rat. Neuroscience 155:128-137.

Stirling DP, Liu S, Kubes P, Yong VW (2009) Depletion of Ly6G/Gr-1 leukocytes after spinal cord injury in mice alters wound healing and worsens neurological outcome. J Neurosci 29:753-764.

Stokoe D, Engel K, Campbell DG, Cohen P, Gaestel M (1992) Identification of MAPKAP kinase 2 as a major enzyme responsible for the phosphorylation of the small mammalian heat shock proteins. FEBS Lett 313:307-313.

Taoka Y, Okajima K, Uchiba M, Murakami K, Kushimoto S, Johno M, Naruo M, Okabe H, Takatsuki K (1997) Role of neutrophils in spinal cord injury in the rat. Neuroscience 79:1177-1182.

Thomas T, Timmer M, Cesnulevicius K, Hitti E, Kotlyarov A, Gaestel M (2008) MAPKAP kinase 2 deficiency prevents neurons from cell death by reducing neuroinflammation-relevance in a mouse model of Parkinson's disease. J Neurochem 105:2039-2052.

Thuraisingam T, Xu YZ, Moisan J, Lachance C, Garnon J, Di Marco S, Gaestel M, Radzioch D (2007) Distinct role of MAPKAPK-2 in the regulation of TNF gene expression by Toll-like receptor 7 and 9 ligands. Mol Immunol 44:3482-3491.

Tonai T, Taketani Y, Ueda N, Nishisho T, Ohmoto Y, Sakata Y, Muraguchi M, Wada K, Yamamoto S (1999) Possible involvement of interleukin-1 in cyclooxygenase-2 induction after spinal cord injury in rats. J Neurochem 72:302-309.
Tonai T, Shiba K, Taketani Y, Ohmoto Y, Murata K, Muraguchi M, Ohsaki H Takeda E, Nishisho T (2001) A neutrophil elastase inhibitor (ONO5046) reduces neurologic damage after spinal cord injury in rats. J Neurochem 78:1064-1072.

Underwood DC, Osborn RR, Bochnowicz S, Webb EF, Rieman DJ, Lee JC, Romanic AM, Adams JL, Hay DW, Griswold DE (2000) SB 239063, a p38 MAPK inhibitor, reduces neutrophilia, inflammatory cytokines, MMP-9, and fibrosis in lung. Am J Physiol Lung Cell Mol Physiol 279:L895-L902.

Wang X, Xu L, Wang H, Young PR, Gaestel M, Feuerstein GZ (2002) Mitogen-activated protein kinase-activated protein (MAPKAP) kinase 2 deficiency protects brain from ischemic injury in mice. J Biol Chem 277:43968-43972.

Wells JE, Hurlbert RJ, Fehlings MG, Yong VW (2003a) Neuroprotection by minocycline facilitates significant recovery from spinal cord injury in mice. Brain 126:1628-1637.

Wells JE, Rice TK, Nuttall RK, Edwards DR, Zekki H, Rivest S, Yong VW (2003b) An adverse role for matrix metalloproteinase 12 after spinal cord injury in mice. J Neurosci 23:10107-10115.

Winzen R, Kracht M, Ritter B, Wilhelm A, Chen CY, Shyu AB, Müller M, Gaestel M, Resch K, Holtmann H (1999) The p38 MAP kinase pathway signals for cytokine-induced mRNA stabilization via MAP kinaseactivated protein kinase 2 and an AU-rich region-targeted mechanism. EMBO J 18:4969-4980.

Xiong Y, Rabchevsky AG, Hall ED (2007) Role of peroxynitrite in secondary oxidative damage after spinal cord injury. J Neurochem 100:639-649.

Xu L, Chen S, Bergan RC (2006) MAPKAPK2 and HSP27 are downstream effectors of p38 MAP kinase-mediated matrix metalloproteinase type 2 activation and cell invasion in human prostate cancer. Oncogene 25:2987-2998.

Xu Z, Wang BR, Wang X, Kuang F, Duan XL, Jiao XY, Ju G (2006) ERK1/2 and p38 mitogen-activated protein kinase mediate iNOS-induced spinal neuron degeneration after acute traumatic spinal cord injury. Life Sci 79:1895-1905.

Yang L, Blumbergs PC, Jones NR, Manavis J, Sarvestani GT, Ghabriel MN (2004) Early expression and cellular localization of proinflammatory cytokines interleukin-1beta, interleukin-6, and tumor necrosis factor-alpha in human traumatic spinal cord injury. Spine (Phila Pa 1976) 29:966-971.

Yong VW, Agrawal SM, Stirling DP (2007) Targeting MMPs in acute and chronic neurological conditions. Neurotherapeutics 4:580-589.

Yune TY, Chang MJ, Kim SJ, Lee YB, Shin SW, Rhim H, Kim YC, Shin ML, Oh YJ, Han CT, Markelonis GJ, Oh TH (2003) Increased production of tumor necrosis factor-alpha induces apoptosis after traumatic spinal cord injury in rats. J Neurotrauma 20:207-219.

Yune TY, Lee JY, Jung GY, Kim SJ, Jiang MH, Kim YC, Oh YJ, Markelonis GJ, Oh TH (2007) Minocycline alleviates death of oligodendrocytes by inhibiting pro-nerve growth factor production in microglia after spinal cord injury. J Neurosci 27:7751-7761.

Zhang B, Schmoyer D, Kirov S, Snoddy J (2004) GOTree Machine (GOTM): a web-based platform for interpreting sets of interesting genes using Gene Ontology hierarchies. BMC Bioinformatics 5:16. 